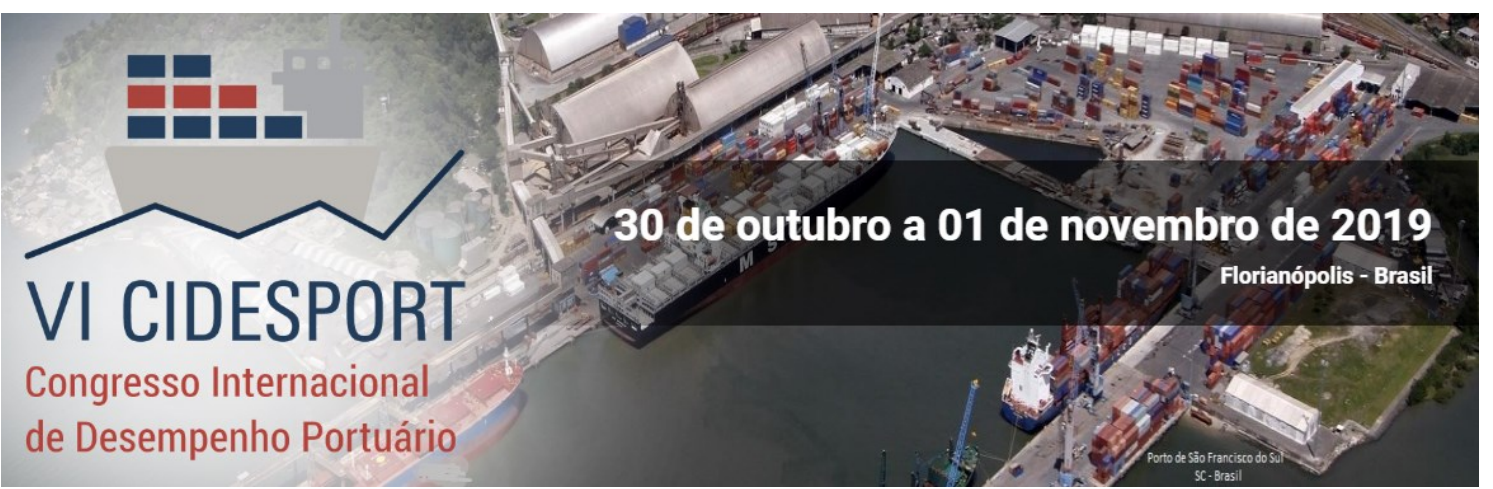

\title{
PREDOMINÂNCIA MASCULINA NA GESTÃO PORTUÁRIA: DESAFIOS À INSERÇÃO DAS MULHERES NA ADMINISTRAÇÃO DAS AUTORIDADES PORTUÁRIAS CATARINENSES
}

\section{Murilo da Silva de Medeiros \\ SCPar Porto de Imbituba}

Resumo: Por que há um baixo número de mulheres nos cargos de gestão das Autoridades Portuárias catarinenses? A partir de um estudo comparativo de caráter quantitativo-estatístico e descritivo, o presente trabalho testou a seguinte hipótese: isso se dá porque os principais pré-requisitos aos cargos de gestão das Autoridades Portuárias no estado de Santa Catarina, isto é, 1) possuir formação e experiência nas áreas de Administração e Gestão; 2) possuir formação e experiência na área Portuária e 3) ser politicamente bem engajado e relacionado, são predominantemente masculinos neste contexto. Após a análise de indicadores aferidos a partir dos três pré-requisitos componentes da hipótese central, constatou-se que a mesma hipótese não serve para responder a pergunta de pesquisa. Conclui-se que o pré-requisito formação e experiência na área de Gestão e Administração não é predominantemente masculino e que, de modo geral, embora significativamente menos presentes no mercado de trabalho relativo aos três pré-requisitos trabalhados, as mulheres estão em relativa igualdade aos homens em termos de formação educacional, ou seja, razoavelmente aptas para ingressarem, sob seus méritos próprios, nos altos cargos de gestão destas e de outras organizações.

Palavras-chave: Desafios à Inserção Feminina no Mercado de Trabalho. Gestão Portuária. Igualdade de gênero.

\section{INTRODUÇÃO}

De modo geral, o mercado de trabalho do Brasil reflete grandes desdobramentos provenientes da desigualdade de gênero. As brasileiras possuem níveis de escolaridade, em várias situações, superiores; estão, cada vez mais, assumindo o caráter de figura de referência na família e são responsáveis por grande parte das tarefas domésticas. Mesmo assim, são desvalorizadas em muitos dos ambientes de trabalho e,em grande parte das situações,recebem remunerações consideravelmente inferiores às dos homens, ocupam um número muito pequeno de cargos de liderança e lidam com barreiras sociais de cunho sexista para a progressão profissional.

A indústria marítima, por sua vez, ainda permanece como umas das mais masculinizadas no mundo (PORTSTRATEGY, 2017). Na esfera portuária brasileira, a prevalência masculina é perceptível a um olhar não, necessariamente, tão atento. Os homens são quantitativamente superiores às mulheres não só nos cargos operacionais ou administrativos, mas,também, nos de gestão e liderança. Os Presidentes, Superintendentes, Conselheiros Administrativos e Diretores portuários

*A revisão gramatical, ortográfica, ABNT ou APA foi realizada pelos autores. 


\section{CIDESPORT/2019}

Congresso Internacional

de Desempenho Portuário

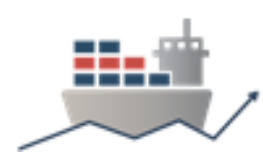

têm um perfil predominantemente masculino. Poucos são os portos, mesmo em nível global, que se assemelham ao Porto de San Diego, na Califórnia, onde metade da liderança executiva, inclusive a Presidente Executiva e duas dos três Vice-Presidentes Executivos, são mulheres (PORT OF SAN DIEGO, 2018).

É inegável que, cada vez mais, amplia-se o feminino nas mais distintas searas da sociedade contemporânea, mas o caminho a ser percorrido para se dirimir a desigualdade de gênero no âmbito dos espaços de poder ainda é bastante árduo e, provavelmente, será longo. Além disso, no que toca ao recorte aqui em evidência, os estudos de cunho acadêmico-científico na área portuária são dominados por temas técnicos. Avançou-se, recentemente, em abordagens de caráter socioambiental, onde o elemento natural é estudado a partir de uma perspectiva social, atrelando-se o desenvolvimento à sustentabilidade nos meios de produção, logística e gestão. A grande maioria dos congressos e demais eventos acadêmico-científicos de relevância quanto ao tema no país, por exemplo, dedicam espaços exclusivos a tais discussões (CIDESPORT, 20191; FATECLOG, 2019; SIMPÓSIO DE GESTÃO PORTUÁRIA, 2019). Entretanto, ainda há déficits no que se refere a estudos que abordem temas sociais outros que fujam ao espectro socioambiental. Há muito a se trabalhar, por exemplo, no campo de relacionamento entre o porto e a cidade ou, ainda, em análises críticas dos processos de gestão e liderança.

Nesse sentido, no que toca à ocupação dos cargos de gestão das Autoridades Portuárias catarinenses, há um número muito baixo de mulheres e este é um pressuposto deste trabalho, pautado, principalmente, na experiência e observação do autor.É tendo isto em vista e diante do contextualizado cenário que o presente estudo se aplica. Logo, a pergunta de pesquisa guia dos esforços do artigo é a seguinte: por que há um baixo número de mulheres nos cargos de gestão das Autoridades Portuárias catarinenses?A hipótese apresentadaatesta que isso se dá porque os principais pré-requisitos aos cargos de gestão das Autoridades Portuárias no estado de Santa Catarina, isto é,1) possuir formação e experiência nas áreas de Administração e Gestão; 2) possuir formação e experiência na área Portuária e 3) ser politicamente bem engajado e relacionado, são predominantemente masculinos.

Assim, a partir de um estudo de caráter crítico-propositivo e de um recorte regional, testando-se a hipótese previamente apresentada, buscou-se verificar os motivos pelos quais há um baixo número de mulheres noscargos de gestão das Autoridades Portuárias catarinenses. Para tanto, refletiu-se sobre a (des)igualdade de gênero no contexto em questão; identificaram-se indicadores que, no tocante à área de gestão e portos, possam, minimamente, aferir informações sobre a formação e experiência feminina; identificaram-se indicadores que possam, minimamente, aferir o relacionamento e engajamento político feminino no presente contexto político e analisaram-setais indicadores de forma comparativa a partir da análise estatística. Metodologicamente, cada um dos objetivos específicos anteriormente listados constituiu uma etapa e um título do trabalho. Ao final, após o teste de cada um dos critérios trazidos pela hipótese central por meio da aferição, comparação e análise dos seus indicadores, a mesma hipótese foireavaliada e uma conclusão propositivafoisugerida.

\section{DESIGUALDADE DE GÊNERO: REFLEXÕES E ASSUNÇÕES}

Vive-se em uma sociedade desigual em termos de gênero. A desigualdade de gênero constitui uma estrutura social intangível, mas palpável por meio das ações, reações e emoções emanadas do meio intersubjetivo. Apresenta-se desde os gestos 


\section{CIDESPORT/2019}

Congresso Internacional

de Desempenho Portuário

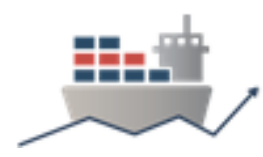

mais simplórios, como um comentário de cunho sexistaem uma conversa de corredor, até os mais agressivos, como nos casos de agressões físicas no contexto familiar. Inicia-se a partir de preconcepções que tendem a taxar uma mulher a partir de seu próprio gênero, a partir de suas vestimentas, desua personalidade ou de qualquer outra coisa que não se encaixe no pré-estabelecido como inerente à identidade feminina, portanto estranho e, consequentemente, motivo da estereotipação geralmente depreciativa (VIEIRA, 2005). Como consequências últimas, segrega mulheres, perpetua injustiças, é condescendente com a violência e estabelece hierarquias.

A hierarquia de gênero trata-se apenas de uma das mais distintas formas de hierarquização social vigentes. Somada às hierarquias econômicas, políticas, epistêmicas, simbólicas, geográficas, culturais, raciais etc., uma grande rede inerente do processo social estabelece-se e tende a moldar os fatos sociais, implicando em drásticas consequências àqueles que se encontram na base, em detrimento daqueles que se posicionam logo acima (DUSSEL, 1977; MIGNOLO, 2000).

A estrutura hierárquica de gênero se constitui a partir de uma histórica divisão sexual dos papeis do que se conhece por "masculino" e "feminino". Tal divisão acaba por perpetuar algo que as feministas estadunidenses da década de 1970 chamaram de 'teto de vidro', ou seja, as mais diversas barreiras invisíveis e artificiais, fruto do preconceito e da discriminação pré-concebida nesta sociedade de papeis de gênero bem divididos e que bloqueiam o acesso das mulheres aos cargos de alto nível hierárquico nas instituições de forma geral (LAVINAS; VEIGA; GUERREIRO, 2011).

No que toca ao mercado de trabalho, as empresas funcionam enquanto famílias patriarcais e as implicações diretas da desigualdade e da hierarquia de gênero estabelecida em uma sociedade patriarcal são as mais diversas, como maiores entraves e desafios à inserção feminina, à progressão de carreira e à equiparação salarial em relação aos homens. No que toca à equiparação salarial em relação aos homens, por exemplo, segundo a Pesquisa Nacional por Amostra de Domicílios Contínua, de 2015, as mulheres dedicam, em média, 8,1 anos aos estudos, enquanto os homens dedicam 7,7 anos. Entretanto, o rendimento médio mensal das mulheres brasileiras é de $R \$ 1.522,00$, enquanto o masculino é de $R \$ 2.012,00$, um valor mais de $24 \%$ superior (IBGE, 2018). Em Santa Catarina, a situação é ainda mais alarmante: mesmo tendo números educacionais mais elevados que os homens em muitos quesitos, como o de Educação Superior - $13,67 \%$ da população catarinense de mulheres e $11,35 \%$ de homens - o rendimento médio feminino é cerca de $53,3 \%$ menor, segundo dados do Programa das Nações Unidas para o Desenvolvimento (PNUD, 2018).

Tais discrepâncias e inconsistências se perpetuam nas mais diversas áreas de atuação profissional. A indústria marítima, em específico, permanece como umas das mais masculinizadas do mundo (PORTSTRATEGY, 2017). Na esfera portuária brasileira, a prevalência masculina é perceptível a um olhar não, necessariamente, tão atento. $\mathrm{O}$ mesmo pode se dizer em relação à esfera portuária catarinense. Conforme evidenciado no quadro 01 , elaborado a partir de dados fornecidos pelas Autoridades Portuárias catarinenses por meio dos seus Portais da Transparência, apenas $18 \%$ dos seus colaboradores são do sexo feminino. 


\section{CIDESPORT/2019}

Congresso Internacional

de Desempenho Portuário

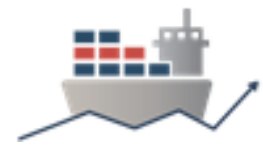

Quadro 1-Quantidade de colaboradores das Autoridades Portuárias catarinenses por sexo (2018)

\begin{tabular}{|l|c|c|c|}
\cline { 2 - 4 } \multicolumn{1}{c|}{} & $\mathbf{N}^{\circ}$ de Homens & $\mathbf{N}^{\circ}$ de Mulheres & TOTAL \\
\hline Imbituba & $74(79 \%)$ & $20(21 \%)$ & $94(100 \%)$ \\
\hline Itajaí & $133(82 \%)$ & $30(18 \%)$ & $163(100 \%)$ \\
\hline Itapoá & $608(81 \%)$ & $142(19 \%)$ & $750(100 \%)$ \\
\hline Portonave & $688(85 \%)$ & $118(15 \%)$ & $806(100 \%)$ \\
\hline São Francisco do Sul & $139(76 \%)$ & $43(24 \%)$ & $182(100 \%)$ \\
\hline TOTAL: & $\mathbf{1 6 4 2 ( 8 2 \% )}$ & $\mathbf{3 5 3 ( 1 8 \% )}$ & $\mathbf{1 9 9 5}(\mathbf{1 0 0} \%)$ \\
\hline
\end{tabular}

Fonte: elaborado pelo autor.

Além disso, dos cargos ocupados pelas mulheres nesses portos, a grande maioria diz respeito aos níveis tático e operacional, sobretudo em demandas administrativas. Em pouquíssimas ocasiões os trabalhos se dão no nível estratégico e a partir de demandas de gestão. No Porto de Itapoá, por exemplo, o maior grupo de mulheres comporta profissionais atuando enquanto Menores Aprendiz - 18 mulheres. No Porto de Imbituba, os maiores grupos estão trabalhando na área administrativa -Administrativas Portuárias e Analistas de Gestão - 8 mulheres no total. Na Portonave, os maiores grupos também estão trabalhando na área administrativa 78 mulheres - e o mesmo pode se dizer em relação ao Porto de São Francisco do Sul - 38 mulheres, dentre Agentes e Técnicas Administrativas(PORTO DE IMBITUBA, 2019; PORTO DE ITAJAÍ, 2019; PORTO DE ITAPOÁ, 2019; PORTO DE SÃO FRANCISCO DO SUL, 2019; PORTONAVE, 2019).

$E$ os homens são quantitativamente superiores às mulheres não só nos cargos de nível tático e operacional, mas, principalmente, nos estratégicos, de gestão e liderança. Basta acessar os organogramas das Autoridades Portuárias para constatar que os Presidentes, Superintendentes, Conselheiros Administrativos e Diretores portuários têm um perfil predominantemente masculino. Por quais razões este cenário assim configura-se?

\section{GESTÃO PORTUÁRIA PREDOMINANTEMENTE MASCULINA: PRÉ- REQUISITOS AOS CARGOS DE GESTÃO NAS AUTORIDADES PORTUÁRIAS CATARINENSES}

A hipótese central deste trabalho é a de que os principais pré-requisitos aos cargos de gestão das Autoridades Portuárias no estado de Santa Catarinasão predominantemente masculinos e, por isso, o baixo número de mulheres nos cargos de liderança e gestão das Autoridades Portuárias.Primordialmente, então, faz-se necessário delimitar o que significa ser predominantemente masculino. Não se trata, pois, de um argumento moral ou normativo, mas tão somente factual, ou seja, dizer que um cargo é predominantemente masculino, em um dado contexto, significa constatar que a maior parte - a parte predominante - dos ocupantes deste cargo, no contexto, é do sexo masculino. Tal constatação, por ser factual, pode ser comprovada ou não a partir da análise dos dados disponíveis. Embora, com base em observação prévia do presente autor sem a utilização de instrumentos de análise estatística, possa-se atestar que o ambiente portuário é predominantemente masculino constituindo-se esse enquanto o principal pressuposto deste trabalho - ao aferir os indicadores estratégicos, sobretudo àqueles ligados à experiência profissional feminina no setor portuário, poder-se-á, também, testar o referido pressuposto.

Em relação aos pré-requisitos componentes da hipótese, o primeiro deles, possuir formação e experiência profissional nas áreas de Administração e Gestão, é 


\section{CIDESPORT/2019}

Congresso Internacional

de Desempenho Portuário

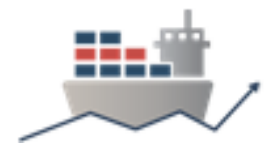

autoevidente, uma vez que, tratando-se de cargos de gestão, portanto, cuja atuação se dá no nível estratégico da organização, parece razoável que o ocupante do cargo possua conhecimentos, habilidades e competências de Administração e Gestão. O segundo critério, isto é, possuir formação e experiência profissional na área portuária, também é claro, uma vez que, tratando-se uma Autoridade Portuária de uma empresa do setor portuário, parece razoável que o ocupante do cargo possua conhecimentos, habilidades e competências do setor portuário.

Por fim, o terceiro pré-requisito, isto é, ser politicamente bem engajado e relacionado, parece menos evidente. Entretanto, o argumento que levou o presente autor a incluir este pré-requisito na hipótese central do trabalho é o seguinte: das cinco Autoridades Portuárias dos portos catarinenses - sem considerar, aqui, o porto pesqueiro de Laguna - três delas são públicas, isto é, a SCPar Porto de Imbituba S.A., Autoridade Portuária do Porto Organizado de Imbituba; a SCPar Porto de São Francisco do Sul S.A., Autoridade Portuária do Porto Organizado de São Francisco do Sul; e a Porto de Itajaí, Autoridade Portuária do Porto de Itajaí. Isto significa dizer que uma quantidade razoável dos altos cargos de gestão destes portos, nos quais se incluem os cargos de Presidente, Superintendente, Diretor e Conselheiro Administrativo, são preenchidos por meio de indicações das autoridades políticas ligadas diretamente a estas organizações, isto é, o estado de Santa Catarina, para o caso das duas primeiras, e o município de Itajaí, para o caso da última.

Além disso, faz-se importante dizer que é certo que existe uma série de outros pré-requisitos para que alguém venha a ocupar um cargo de gestão em uma Autoridade Portuária catarinense, porém, os três pré-requisitos aqui em evidência, a partir da hipótese formulada por este autor, constituem-se enquanto aqueles de maior contundência e, por isso, compõem a hipótese central proposta.

\subsection{Formação e experiência feminina em administração e gestão}

A presente seção, bem como a seção seguinte, visará a suprir o primeiro objetivo específico do trabalho, isto é, identificar indicadores que, no tocante à área de gestão e portos, possam, minimamente, aferir informações sobre a formação e experiência feminina.Tais indicadores foram buscados a partir de critérios delimitativos de tempo (quando), espaço (onde), conceito (o que) e natureza (qualitativa ou quantitativa).

No que toca à formação acadêmica e experiência profissional feminina na área de Administração e Gestão, cabe dividir os indicadores a serem identificados em duas categorias. Para a primeira delas, relacionada à formação, buscou-se um conjunto de indicadores que seguisse os seguintes critérios:

a) (Tempo) Possuir como data-base um período de, no máximo, cinco anos;

b) (Espaço) Trazer informações espaciais sobre a experiência feminina de forma Multinível e regressiva, onde o globo constitui-se enquanto o mais alto nível e o estado de Santa Catarina o mais baixo;

c) (Natureza) Ser passível de meça numérica;

d) (Conceito) Trazer informações sobre a formação feminina de forma Multinível e regressiva, onde o Doutorado constitui-se enquanto o mais alto nível e a Graduação o mais baixo. 


\section{CIDESPORT/2019}

Congresso Internacional

de Desempenho Portuário

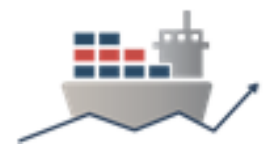

Por sua vez, os critérios aplicados na busca do conjunto de indicadores para a segunda categoria, isto é, relacionada à experiência feminina, foram os seguintes:

e) (Tempo) Possuir como data-base um período de, no máximo, cinco anos;

f) (Espaço) Trazer informações espaciais sobre a experiência feminina de forma Multinível e regressiva, onde o globo constitui-se enquanto o mais alto nível e o estado de Santa Catarina o mais baixo;

g) (Natureza) Ser passível de meça numérica;

h) (Conceito) Focar no nível estratégico de gestão e não no tático e operacional.

A partir de uma busca em uma série de bases de dados públicas, identificaram-se oito indicadores provenientes de cinco bases de dados distintas que seencaixam nos critérios estabelecidos. O quadro 02 compila os indicadores identificados já com o resultado da aferição para anos de referência devidamente identificados no mesmo quadro.

Quadro 2 - Indicadores relativos ao primeiro pré-requisito: formação e experiência feminina nas áreas de Administração e Gestão

\begin{tabular}{|c|c|c|c|c|c|c|c|}
\hline Indicador & $\begin{array}{l}\text { Relação com } \\
\text { "Formação" ou } \\
\text { "Atuação"? }\end{array}$ & Homens & Mulheres & $\begin{array}{l}\text { Proporção de } \\
\text { Mulheres }\end{array}$ & Ref. & Discrepãncia? & Fonte \\
\hline $\begin{array}{l}\text { Número de mulheres CEOs nas } 500 \text { maiores } \\
\text { empresas do mundo, segundo o índice Fortune 500, } \\
\text { em comparação ao número de homens. }\end{array}$ & Atuação & 436 & 64 & $12,80 \%$ & 2019 & Sim & \multirow{2}{*}{ Fortune (2019). } \\
\hline $\begin{array}{l}\text { Número de mulheres CEOs nas } 120 \text { maiores } \\
\text { empresas do Brasil, segundo o İndice Fortune 500, } \\
\text { em comparação ao número de homens. }\end{array}$ & Atuação & 115 & 5 & $4,17 \%$ & 2014 & Sim & \\
\hline $\begin{array}{l}\text { Número de mulheres CEOs nas } 50 \text { maiores } \\
\text { empresas catarinenses, segundo o índice } 500 \\
\text { Maiores do Sul (do Brasil), em comparação ao } \\
\text { número de homens. }\end{array}$ & Atuação & 45 & 5 & $10,00 \%$ & 2019 & Sim & $\begin{array}{l}\text { CNPJ Consultas } \\
\text { (2019). }\end{array}$ \\
\hline $\begin{array}{l}\text { Número de mulheres com título de Mestrado ou } \\
\text { Doutorado no Currículo Lattes, na Grande Área das } \\
\text { Ciências Sociais Aplicadas, em comparação ao } \\
\text { número de homens. }\end{array}$ & Formação & 15201 & 13085 & $46,26 \%$ & 2016 & Não & CNPQ (2019). \\
\hline $\begin{array}{l}\text { Número de mulheres matriculadas nos cursos de } \\
\text { pós-graduação (mestrado) da Grande Área } \\
\text { "ADMINISTRAÇÃO PÚBLICA E DE EMPRESAS, } \\
\text { CIÊNCIAS CONTÁBEIS E TURISMO" em } \\
\text { comparação ao número de homens. }\end{array}$ & Formação & 3317 & 2679 & $44,68 \%$ & 2017 & Não & \multirow{2}{*}{ CAPES (2019). } \\
\hline $\begin{array}{l}\text { Número de mulheres matriculadas nos cursos de } \\
\text { pós-graduação (doutorado) da Grande Área } \\
\text { "ADMINISTRAÇÃO PÚBLICA E DE EMPRESAS, } \\
\text { CIÊNCIAS CONTÁBEIS E TURISMO" em } \\
\text { comparação ao número de homens. }\end{array}$ & Formação & 2567 & 2358 & $47,88 \%$ & 2017 & Não & \\
\hline $\begin{array}{l}\text { Número de mulheres matriculadas nos cursos } \\
\text { nacionais de Bacharelado em Administração em } \\
\text { comparação ao número de homens. }\end{array}$ & Formação & 314966 & 396018 & $55,70 \%$ & 2016 & Não & INEP (2019). \\
\hline $\begin{array}{l}\text { Número de mulheres docentes na área de } \\
\text { Administração nos cursos de pós-graduação stricto- } \\
\text { sensu em relação ao número de homens. }\end{array}$ & Formação / Atuação & 2458 & 1224 & $33,24 \%$ & 2017 & Sim & CAPES (2019). \\
\hline
\end{tabular}

Fonte: Elaboração do autor.

O quadro 2, além do quadro 3 e 4 - adiante apresentados - enumeram os indicadores de forma cardinal, apresentam a descrição dos indicadores, apontam se os indicadores relacionam-se à formação acadêmica ou experiência profissional, informam os valores totais da quantidade de homens e mulheres, bem como o valor percentual de mulheres em relação ao de homens, apresentam os anos da aferição e informam se elas apresentaram resultados discrepantes ou não.

Quanto à última coluna, isto é, relativa à discrepância proporcional do número de mulheres em relação ao de homens, o critério adotado foi o seguinte: para os casos em que a proporção de mulheres é inferior a $40 \%$ ou superior a $60 \%$, constatou-se discrepância; para os casos em que os valores ficaram entre $40 \%$ e $60 \%$, constatou-se a não discrepância. Para os casos inferiores a $40 \%$, a 


\section{CIDESPORT/2019}

Congresso Internacional

de Desempenho Portuário

discrepância atestada significa que há um número muito baixo de mulheres proporcionalmente ao de homens no que toca ao indicador em questão. Para os casos superiores a $60 \%$ - nenhuma ocorrência no contexto deste trabalho - a discrepância significaria que há um número muito baixo de homens proporcionalmente ao de mulheres no que toca ao indicador em questão.

Feitas tais devidas considerações, é possível avançar para a análise dos dados coletados. Três foram os indicadores medidos relacionados à atuação profissional, quatro em relação à formação acadêmica e um em relação aos dois elementos de forma concomitante. Todos os três indicadores relativos à atuação profissional apresentaram valores discrepantes e em nenhum deles o percentual de mulheres superou a marca de $15 \%$. Isso significa dizer que, no indicador onde o percentual de mulheres comparadoao de homens obteve o maior resultado $-12,8 \%$ de mulheres CEOs nas quinhentas maiores empresas do mundo, segundo o índice Fortune 500 -o percentual de homens comparado ao de mulheres é de $87,2 \%$, um número quase sete vezes maior (FORTUNE, 2019).

Além disso, dos três níveis pesquisados, global, nacional e estadual, o nacional foi o que obteve os resultados proporcionais femininos mais baixos, isto é, $4,17 \%$ (FORTUNE, 2019), atrás do estadual, com 10\%, e do global, com 12,8\% (CNPJ CONSULTAS, 2019). Isto significa dizer que o estado de Santa Catarina apresenta, no que toca à natureza dos indicadores aferidos, um percentual de mulheres superior à média nacional, mas ainda inferior à global. Em outras palavras, mesmo puxando a média nacional para cima, ainda se está aquém da média global e muito mais aquém, ainda, da média dos países centrais da América do Norte e Europa, que puxam a média global para cima.

Por outro lado, no que toca aos indicadores medidos em relação à formação acadêmica, as constatações são bastante distintas. Isto porque nenhum dos quatro indicadores apresentou discrepância na proporção de mulheres em relação aos homens. Em um deles, inclusive - número de mulheres matriculadas nos cursos nacionais de Bacharelado em Administração em comparação ao número de homens - o porcentual feminino - de $55,7 \%$ - foi superior ao percentual masculino - de $44,3 \%$. Em nenhum dos indicadores o percentual feminino foi inferior a $44 \%$, uma vez que o indicador que apresentou o resultado mais baixo - número de mulheres matriculadas nos cursos de pós-graduação (mestrado) da Grande Área "Administração Pública ede Empresas, Ciências Contábeis e Turismo" em comparação ao número de homens obteve 44,68\% (CAPES, 2017; CNPQ, 2019; INEP, 2019). É importante dizer, também, que não se conseguiu aferir indicadores relativos à formação acadêmica em Gestão e Administração nas esferas global e estadual, conforme assim estabeleceuse a partir do critério ' $b$ ', anteriormente evidenciado. Esta se constitui enquanto uma limitação do presente trabalho, uma vez que não se identificaram, por hora, bases de dados nestas esferas que pudessem suprir as informações desejadas.

O último indicador aferido, por sua vez, aquele relativo tanto à formação acadêmica quanto à experiência profissional, isto é, número de mulheres docentes na área de Administração nos cursos de pós-graduação stricto-sensu em relação ao número de homens, apresentou um valor discrepante - de 33,24\% (CAPES, 2017). No contexto do indicador, há, praticamente, dois homens para cada mulher. Entretanto, tal discrepância ainda é bastante menor que a discrepância observada para o primeiro grupo de indicadores, isto é, aqueles relativos à atuação profissional.

\subsection{Formação e experiência feminina na área portuária}




\section{CIDESPORT/2019}

Congresso Internacional

de Desempenho Portuário

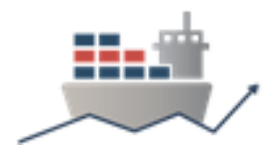

No que toca à formação e experiência feminina na área portuária, cabe dividir os indicadores buscados em duas categorias. Para a primeira delas, relacionada à formação, buscou-se um conjunto de indicadores que seguisse os seguintes critérios:

a) (Tempo) Possuir como data-base um período de, no máximo, cinco anos;

b) (Espaço) Trazer informações do contexto nacional e estadual;

c) (Natureza) Ser passível de meça numérica;

d) (Conceito) Trazer informações sobre a formação feminina de forma Multinível e regressiva, onde o Doutorado constitui-se enquanto o mais alto nível e a Graduação o mais baixo.

Por sua vez, os critérios aplicados na busca do conjunto de indicadores para a segunda categoria, isto é, relacionada à experiência feminina, foram os seguintes:

e) (Tempo) Possuir como data-base um período de, no máximo, cinco anos;

f) (Espaço) Trazer informações do contexto nacional e estadual;

g) (Natureza) Ser passível de meça numérica;

h) (Conceito) Focar no nível estratégico de gestão, e não no tático e operacional.

A partir de uma busca em uma série de bases de dados públicas, identificaram-se nove indicadores provenientes de nove bases distintas que se encaixam nos critérios estabelecidos. O quadro 03 compila os indicadores identificados já com o resultado da aferição para anos de referência devidamente identificados no mesmo quadro. 


\section{CIDESPORT/2019}

\section{Congresso Internacional}

de Desempenho Portuário

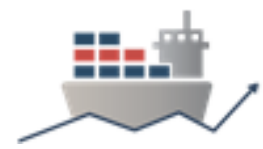

Quadro 3 - Indicadores relativos ao segundo pré-requisito: formação e experiência feminina na área portuária

\begin{tabular}{|c|c|c|c|c|c|c|c|}
\hline Indicador & $\begin{array}{l}\text { Relação com } \\
\text { "Formação" ou } \\
\text { "Atuação"? }\end{array}$ & Homens & Mulheres & $\begin{array}{c}\text { Proporção de } \\
\text { Mulheres }\end{array}$ & Ref. & Discrepãncia? & Fonte \\
\hline $\begin{array}{l}\text { Número de mulheres matriculadas nos cursos de } \\
\text { pós-graduação stricto-sensu em "Logística" em } \\
\text { comparação ao número de homens. }\end{array}$ & Formação & 28 & 21 & $42,86 \%$ & 2019 & Não & CAPES (2019). \\
\hline $\begin{array}{l}\text { Número de mulheres que, nos últimos } 10 \text { anos, em } \\
\text { programas de pós-graduação do Brasil, } \\
\text { defenderam dissertação de mestrado ou tese de } \\
\text { doutorado em cujo título conste pelo menos um dos } \\
\text { termos-chave: "Gestão Portuária" / "Administração } \\
\text { Portuária" / "Setor Portuário", em comparação ao } \\
\text { número de homens. }\end{array}$ & Formação & 13 & 5 & $27,78 \%$ & 2017 & Sim & CAPES (2017). \\
\hline $\begin{array}{l}\text { Número de mulheres ocupando cargo de } \\
\text { Presidente, Vice-Presidente ou Diretor na } \\
\text { Associação Brasileira das Entidades Portuárias e } \\
\text { Hidroviárias (ABEPH). }\end{array}$ & Atuação & 3 & 0 & $0,00 \%$ & 2019 & Sim & \multirow{5}{*}{$\begin{array}{l}\text { Porto de Imbituba } \\
\text { (2019); Porto de } \\
\text { Itajaí (2019); Portc } \\
\text { de Itapoá (2019); } \\
\text { Porto de São } \\
\text { Francisco do Sul } \\
\text { (2019); Portonave } \\
\text { (2019). }\end{array}$} \\
\hline $\begin{array}{l}\text { Número de mulheres ocupando cargo de Diretor } \\
\text { Presidente ou Superintendente nas Autoridades } \\
\text { Portuárias brasileiras associadas à Associação } \\
\text { Brasileira das Entidades Portuárias e Hidroviárias } \\
\text { (ABEPH).. }\end{array}$ & Atuação & 16 & 1 & $5,88 \%$ & 2019 & Sim & \\
\hline $\begin{array}{l}\text { Número de mulheres ocupando cargo de Presidente } \\
\text { e/ou Superintendente nas Autoridades Portuárias } \\
\text { catarinenses. }\end{array}$ & Atuação & 6 & 0 & $0,00 \%$ & 2019 & $\operatorname{Sim}$ & \\
\hline $\begin{array}{l}\text { Número de mulheres ocupando cargo de Diretor } \\
\text { nas Autoridades Portuárias catarinenses. }\end{array}$ & Atuação & 7 & 1 & $12,50 \%$ & 2019 & Sim & \\
\hline $\begin{array}{l}\text { Número de mulheres ocupando cargo de } \\
\text { Conselheiro de Administração nas Autoridades } \\
\text { Portuárias catarinenses. }\end{array}$ & Atuação & 16 & 2 & $11,11 \%$ & 2019 & Sim & \\
\hline $\begin{array}{l}\text { Número de mulheres ocupando cargo de Gerente } \\
\text { nas Autoridades Portuárias catarinenses. }\end{array}$ & Atuação & 34 & 4 & $10,53 \%$ & 2019 & Sim & \\
\hline $\begin{array}{l}\text { Número de mulheres presentes nas últimas } 3 \\
\text { edições do CIDESPORT em comparação ao } \\
\text { número de homens. }\end{array}$ & Formação / Atuação & 307 & 114 & $27,08 \%$ & $2017-2019$ & Sim & $\begin{array}{l}\text { CIDESPORT } \\
\left(2019^{2}\right)\end{array}$ \\
\hline
\end{tabular}

Fonte: Elaboração do autor.

No que toca à análise dos dados coletados, seis foram os indicadores relacionados à atuação profissional, dois em relação à formação acadêmica e um em relação aos dois elementos de forma concomitante.Todos os seis indicadores relativos à atuação profissional apresentaram resultados discrepantes e em nenhum deles o percentual de mulheres superou a marca de $13 \%$. Isso significa dizer que, no indicador onde o percentual de mulheres comparado ao de homensobteve o maior resultadonúmero de mulheres ocupando o cargo de Diretor ou que o valha nas Autoridades Portuárias catarinenses, ou seja, $12,50 \%$-, o percentual de homens comparado ao de mulheres é de $87,50 \%$, um número sete vezes maior(PORTO DE IMBITUBA, 2019; PORTO DE ITAJAÍ, 2019; PORTO DE ITAPOÁ, 2019; PORTO DE SÃO FRANCISCO DO SUL, 2019; PORTONAVE, 2019).

Além disso, dois indicadores apresentaram valores zerados, isto é, o número de mulheres ocupando cargo de Presidente, Vice-Presidente ou Diretor na Associação Brasileira das Entidades Portuárias e Hidroviárias (ABEPH) e o número de mulheres ocupando cargo de Presidente e/ou Superintendente nas Autoridades Portuárias catarinenses. Isto significa dizer que não há, atualmente, mulheres ocupando os cargos máximos de liderança nas Autoridades Portuárias, tampouco na associação nacional de Autoridades Portuárias. Se levado em consideração os 


\section{CIDESPORT/2019}

Congresso Internacional

de Desempenho Portuário

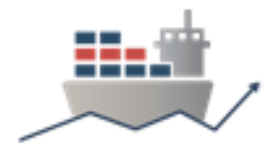

demais indicadores relativos à atuação profissional feminina no ambiente portuário, significa dizer, também, que está confirmada a discrepância entre o número de mulheres e o número de homens atuando profissionalmente nos cargos de gestão das Autoridades Portuárias, pressuposto teórico do presente trabalho $(\mathrm{ABEPH}, 2019$; PORTO DE IMBITUBA, 2019; PORTO DE ITAJAÍ, 2019; PORTO DE ITAPOÁ, 2019; PORTO DE SÃO FRANCISCO DO SUL, 2019; PORTONAVE, 2019).

No que toca aos dois indicadores medidos em relação à formação acadêmica, um deles apresentou resultado não discrepante $-42,86 \%$ de mulheres frente a $57,14 \%$ de homens matriculados nos cursos de pós-graduaçãostricto-sensu em "Logística" - e um deles apresentou resultado discrepante $-27,78 \%$ de mulheres frente a $62,22 \%$ de homens que, nos últimos 10 anos, em programas de pósgraduação do Brasil, defenderam dissertação de mestrado ou tese de doutorado em cujo título conste pelo menos um dos termos-chave: "Gestão Portuária" / "Administração Portuária" / "Setor Portuário", em comparação ao número de homens.Entretanto, tal discrepância ainda é muito menor que a discrepância observada para o primeiro grupo de indicadores, isto é, aqueles relativos à atuação profissional (CAPES, 2017; 2019).

É importante dizer, também, que não se conseguiu aferir indicadores relativos à formação acadêmica no setor portuário na esfera estadual, conforme assim estabeleceu-se a partir do critério 'b', anteriormente evidenciado. Esta se constitui enquanto uma limitação do presente trabalho, uma vez que não se identificaram bases de dados nesta esfera que pudesse suprir as informações desejadas. O mesmo se aplica em relação aos dados da formação acadêmica no nível de graduação, conforme assim estabeleceu-se a partir do critério 'd', anteriormente evidenciado. Isto porque não existem cursos de graduação no Brasil específicos da área portuária e, no que toca ao campo da Logística, preferiu-se coletar dados nos níveis de pós-graduação.

O último indicador aferido,aquele relativo tanto à formação acadêmica quanto à experiência profissional, isto é, à participação femininaem comparação ao número de homens nas últimas 3 edições do Congresso internacional de Desempenho Portuário (CIDESPORT), um dos eventos acadêmico-científicos do setor portuário de maior relevânciano país, também apresentou um valor discrepante - de 27,08\% (CIDESPORT, 2019). No contexto do indicador, há mais de dois homens para cada mulher. Entretanto, tal discrepância ainda é muito menor que a discrepância observada para o primeiro grupo de indicadores, isto é, aqueles relativos à atuação profissional.

\subsection{Relacionamento e engajamento político feminino}

No que toca ao relacionamento e engajamento político feminino, buscouse um conjunto de indicadores que seguisse os seguintes critérios:

a) (Tempo) Possuir como data-base um período de, no máximo, cinco anos;

b) (Espaço e Conceito) Trazer informações no que toca à ocupação dos principais cargos públicos da política nacional;

c) (Espaço e Conceito) Trazer informações no que toca à ocupação dos cargos comissionados - por indicação - no contexto estadual;

d) (Natureza) Ser passível de meça numérica;

A partir de uma busca em uma série de bases de dados públicas, identificaram-se nove indicadores provenientes de cinco bases distintas que se 


\section{CIDESPORT/2019}

\section{Congresso Internacional}

de Desempenho Portuário

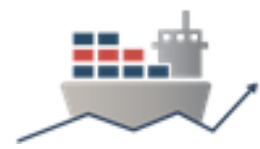

encaixam nos critérios estabelecidos. O quadro 04 compila os indicadores identificados já com o resultado da aferição para anos de referência devidamente identificados no mesmo quadro.

Quadro 4 - Indicadores relativos ao terceiro pré-requisito: relacionamento e engajamento político feminino

\begin{tabular}{|c|c|c|c|c|c|c|c|}
\hline Indicador & $\begin{array}{l}\text { Relação com } \\
\text { "Formação" ou } \\
\text { "Atuação"? }\end{array}$ & Homens & Mulheres & $\begin{array}{l}\text { Proporção de } \\
\text { Mulheres }\end{array}$ & Ref. & Discrepãncia? & Fonte \\
\hline $\begin{array}{l}\text { Número de mulheres atuantes como deputadas } \\
\text { federais em comparação ao número de homens. }\end{array}$ & Atuação & 436 & 77 & $15,01 \%$ & 2019 & Sim & \multirow[t]{2}{*}{ IPU (2019). } \\
\hline $\begin{array}{l}\text { Número de mulheres atuantes como senadoras em } \\
\text { comparação ao número de homens. }\end{array}$ & Atuação & 69 & 12 & $14,81 \%$ & 2019 & Sim & \\
\hline $\begin{array}{l}\text { Número de mulheres atuantes como Presidentes da } \\
\text { República na história da Sexta República brasileira } \\
\text { (pós Ditadura Militar de } 1964 \text { a 1985) em } \\
\text { comparação ao número de homens. }\end{array}$ & Atuação & 8 & 1 & $11,11 \%$ & $1985-2019$ & Sim & $\begin{array}{l}\text { Presidência da } \\
\text { República }\left(2019^{1}\right)\end{array}$ \\
\hline $\begin{array}{l}\text { Número de mulheres atuantes como Ministras em } \\
\text { comparação ao número de homens. }\end{array}$ & Atuação & 20 & 2 & $9,09 \%$ & 2019 & Sim & $\begin{array}{l}\text { Presidência da } \\
\text { República }\left(2019^{2}\right) \text {. }\end{array}$ \\
\hline $\begin{array}{l}\text { Número de mulheres atuantes como Governadoras } \\
\text { em comparação ao número de homens. }\end{array}$ & Atuação & 26 & 1 & $3,70 \%$ & 2019 & Sim & $\begin{array}{l}\text { Presidência da } \\
\text { República }\left(2019^{3}\right)\end{array}$ \\
\hline $\begin{array}{l}\text { Número de mulheres atuantes como deputadas } \\
\text { estaduais em SC em comparação ao número de } \\
\text { homens. }\end{array}$ & Atuação & 35 & 5 & $12,50 \%$ & 2019 & Sim & ALESC (2019). \\
\hline $\begin{array}{l}\text { Número de mulheres ocupando cargos públicos } \\
\text { comissionados sem vínculo efetivo na esfera } \\
\text { estadual em comparação ao número de homens. }\end{array}$ & Atuação & 322 & 259 & $44,58 \%$ & 2019 & Sim & \multirow{3}{*}{$\begin{array}{l}\text { Poder Executivo } \\
\text { do Estado de } \\
\text { Santa Catarina } \\
\text { (2019). }\end{array}$} \\
\hline $\begin{array}{l}\text { Número de mulheres ocupando cargos públicos } \\
\text { comissionados sem vínculo efetivo na esfera } \\
\text { estadual cuja remuneração seja igual ou superior a } \\
\mathrm{R} \$ 10.000,00 \text { ao mês em comparação ao número } \\
\text { de homens. }\end{array}$ & Atuação & 66 & 38 & $36,54 \%$ & 2019 & Sim & \\
\hline $\begin{array}{l}\text { Número de mulheres ocupando cargos públicos } \\
\text { comissionados na área de Administração e Gestão } \\
\text { na esfera estadual em comparação ao número de } \\
\text { homens. }\end{array}$ & Atuação & 167 & 104 & $38,38 \%$ & 2019 & Sim & \\
\hline
\end{tabular}

Fonte: elaboração do autor.

No que toca à análise dos dados coletados, nove foram os indicadores relacionados à atuação profissional e nenhum em relação à formação acadêmica, isto porque o presente autor entende que não existe uma formação prévia ao exercício da política no âmbito nacional. Embora a Ciência Política seja a Ciência que mais bem estuda os processos políticos, outras áreas parecem mais condizer com o exercício dos cargos políticos e com a própria realidade dos políticos brasileiros, como a Administração Pública e o Direito. Além disso, por tratar-se de um pré-requisito que aborda relacionamento e engajamento político, possui relação muito maior com a atuação política que com a formação dos indivíduos. Em virtude disso, optou-se por não aferir indicadores relacionados à formação acadêmica para o presente prérequisito. Salienta-se, ainda, que todos os indicadores para este pré-requisito, com exceção do terceiro, cuja linha temporal vai de 1985 a 2019, foram medidos no ano de 2019.

Dos nove indicadores aferidos, apenas um não apresentou resultados discrepantes, isto é, $44,58 \%$ de mulheres frente a $55,42 \%$ de homens ocupando cargos públicos comissionados sem vínculo efetivo, na esfera estadual. Dois dos indicadores apresentaram discrepância na casa entre 30 e 40\%, isto é, $36,54 \%$ de mulheres frente a $73,46 \%$ de homens ocupando cargos públicos comissionados sem vínculo efetivo, na esfera estadual, cuja remuneração seja igual ou superior a $R \$$ $10.000,00$ ao mês e $38,38 \%$ de mulheres frente a $61,62 \%$ de homens ocupando cargos públicos comissionados na área de Administração e Gestão, na esfera estadual (PODER EXECUTIVO DO ESTADO DE SANTA CATARINA, 2019).

Todos os demais seis indicadores apresentaram resultados discrepantes, ou seja, cujo número de mulheres ficou abaixo de $16 \%$, sendo que o menor percentual 


\section{CIDESPORT/2019}

Congresso Internacional

de Desempenho Portuário

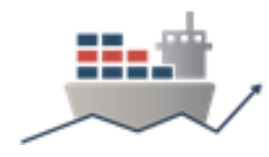

foi o de $3,7 \%$ de mulheres frente aos $96,3 \%$ de homens atuantes como Governadores estaduais. Isto significa dizer que apenas um estado, em 2019, possui uma Governadora - o estado do Rio Grande do Norte; significa que, desde a redemocratização, em 1985, teve-se apenas uma Presidente da República mulher; significa que, dos atuais vinte de dois Ministros do Presidente da República, apenas duas são mulheres; significa que, dos 40 Deputados Estaduais catarinenses, apenas cinco são mulheres; e significa que o número de Deputados Federais e Senadores brasileiros do sexo masculino é quase seis vezes superior ao número de mulheres ocupando estes cargos (ALESC, 2019; IPU, 2019; PRESIDÊNCIA DA REPÚBLICA, $\left.2019^{1}, 2019^{2}, 2019^{3}\right)$. Para o caso de analisarem-se os mesmos indicadores a partir de uma perspectiva histórica, os resultados não serão tão distintos, uma vez que, no Brasil, a política é feita, predominantemente, por homens.

\section{CONSIDERAÇÕES FINAIS}

De modo a viabilizar-se uma análise estatística comparativa dos indicadores aferidos no contexto deste trabalho, o quadro 5 compila e cruza os dados discrepantes e os resultados relativos à formação acadêmica e atuação profissional, enquanto o quadro 6 compila e cruza os dados discrepantes e os resultados relativos aos pré-requisitos ao exercício dos altos cargos de gestão das Autoridades Portuárias catarinenses, estipulados na hipótese central do trabalho.

Quadro 5-Número de indicadores aferidos quanto à formação acadêmica e atuação profissional feminina com valores discrepantes e não discrepantes

\begin{tabular}{|c|c|c|c|c|}
\multicolumn{1}{c|}{} & Formação & Atuação & Formação e Atuação & TOTAL \\
\hline Com Discrepância: & 1 & 18 & 2 & $\mathbf{2 1}$ \\
\hline Sem Discrepância: & 5 & 0 & 0 & $\mathbf{5}$ \\
\hline TOTAL & $\mathbf{6}$ & $\mathbf{1 8}$ & $\mathbf{2}$ & $\mathbf{2 6}$ \\
\hline
\end{tabular}

Fonte: elaborado pelo autor.

Quadro 6 - Número de indicadores aferidos em cada um dos pré-requisitos aos cargos de gestão das Autoridades Portuárias com valores discrepantes e não discrepantes

\begin{tabular}{|c|c|c|c|c|}
\cline { 2 - 5 } \multicolumn{1}{c|}{} & $\mathbf{1}^{\mathbf{0}}$ Pré-Requisito & $\mathbf{2}^{\mathbf{0}}$ Pré-Requisito & $\mathbf{3}^{\circ}$ Pré-Requisito & TOTAL \\
\hline Com Discrepância: & 4 & 8 & 9 & $\mathbf{2 1}$ \\
\hline Sem Discrepância: & 4 & 1 & 0 & $\mathbf{5}$ \\
\hline TOTAL & $\mathbf{8}$ & $\mathbf{9}$ & $\mathbf{9}$ & $\mathbf{2 6}$ \\
\hline
\end{tabular}

Fonte: elaborado pelo autor.

A partir disso, pode atestar-se que a hipótese central deste trabalho, isto é, a de que os principais pré-requisitos aos cargos de gestão das Autoridades Portuárias no estado de Santa Catarinasão predominantemente masculinos, não se comprovou após os testes realizados via a aferição dos indicadores. Isto porque:

1) Quanto ao primeiro pré-requisito, isto é, formação e experiência na área de Gestão e Administração, o número de indicadores que apresentaram resultados discrepantes e o número de indicadores que não apresentaram resultados discrepantes é igual, ou seja, 4 (quatro). Isto significa dizer que se identificaram discrepâncias no que toca ao número de mulheres em relação ao de homens nos indicadores do segundo e do terceiro pré-requisito, isto é, formação e experiência profissional na área portuária e relacionamento e engajamento político, mas o mesmo não pode ser dito em relação ao primeiro pré-requisito. Ou seja, o pré-requisito formação e experiência na área de Gestão e Administração não é 


\section{CIDESPORT/2019}

Congresso Internacional

de Desempenho Portuário

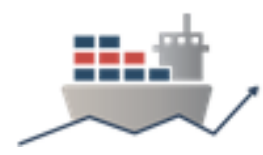

predominantemente masculino. Entretanto, para uma melhor compreensão dos dados obtidos, faz-se necessário uma segunda consideração:

2) No que toca aos indicadores relativos à experiência profissional de todos os pré-requisitos, identificou-se significativa discrepância entre o número de mulheres e de homens, mas no que toca aos indicadores relativos à formação acadêmica, o mesmo não foi observado, uma vez que a maior parte destes indicadores apresentam dados não discrepantes. Ou seja, embora significativamente menos presentes no mercado de trabalho relativo aos três pré-requisitos trabalhados, as mulheres estão em relativa igualdade aos homens em termos de formação educacional. Isso implica em dizer que, embora possuam as precondições formativas, não estão, efetivamente, empregadas e atuantes no mercado de trabalho.

Dado o exposto, não cabe validar a proposição inicial deste trabalho, isto é, a de que o baixo número de mulheres nos cargos de gestão das Autoridades Portuárias catarinenses se dá porque os propostospré-requisitos para a integração desses cargos são predominantemente masculinos. Entretanto, a partir da perspectiva científica popperiana de que não cabe à Ciência dizer o que é verdadeiro, mas o que é falso, poder isso constatar já se constitui enquanto um avanço no que toca ao tratamento do tema.

Além disso, mesmo a pergunta de pesquisa do atual trabalho, isto é, "por que há um baixo número de mulheres nos cargos de gestão das Autoridades Portuárias catarinenses?" não tendo sido respondida satisfatoriamente pela hipótese apresentada, surge, a partir desta conclusão, uma outra pergunta, dessa derivada e ainda mais refinada, qual seja: por que a formação acadêmica feminina não está sendo suficiente para a sua ocupação dos cargos de gestão das Autoridades Portuárias catarinenses?A partir do novo questionamento proposto, abre-se caminho para se explorar novos meandros da temática não abordados pelo presente trabalho. Na perspectiva deste autor, as Teorias Feministas possuem argumentações que podem responder de maneira minimamente satisfatória tal problemática, entretanto, esta é uma tarefa para trabalhos futuros que, assim esperase, possam utilizar-se das contribuições realizadas pelo atual trabalho.

Em termos de proposições atitudinais, partindo-se de uma perspectiva transformativa da Ciência, ou seja, que visualiza que, mais que apenas problematizar, criticar e atestar, é papel do pesquisador, a partir dos conhecimentos adquiridos do processo científico, propor soluções para resolução dos problemas identificados, o autor reafirma as sugestões realizadas pela União Europeia (2008)em seu Manual para a Integração da Dimensão da Igualdade de Gênero nas Políticas de Emprego, em confluência com as contribuições advindas da própria AdvancingWoman in Transportation (WTF, 2019), organização internacional que aborda a temática da inserção feminina no setor logístico, ou seja, que sejam cada vez mais visadas, no âmbito portuário, as políticas de conformidade, tais como as políticas ativas do mercado de trabalho, políticas de remuneração e carreira, políticas de conciliação e políticas de flexigurança.

Ainda sob o ponto de vista atitudinal, mas, neste momento, tendo em vista que o presente autor fala sob o ponto de vista masculino, salienta-se a necessidade de que os homens compreendam o seu papel na busca por uma sociedade de maior igualdade de gênero. Ainda que outras tantas macrovisões e possibilidades teóricas e práticas possam se aplicar ao problema aqui trazido e a outros tantos do universo social, conscientizar-se, reconhecer o embalanço e agir para seu equilíbrio parece ser um primeiro passo oportuno e pertinente. 


\section{CIDESPORT/2019}

Congresso Internacional

de Desempenho Portuário

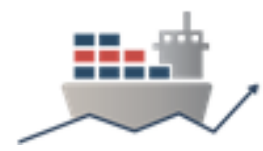

Por último, as possibilidades de ampliação da pesquisa aqui em questão são evidentes. De modo a qualificar as conclusões realizadas, pode-se ampliar o número de indicadores aferidos a partir da ampliação do universo de pesquisa. Podese, por exemplo, considerar-se não apenas os portos catarinenses, mas também os demais portos brasileiros. Além disso, um trabalho futuro pode considerar não apenas as Autoridades Portuárias, mas, também, outros tantos importantes atores do contexto portuário, como arrendatários, armadores e operadores. Existe a possibilidade, da mesma maneira, de aferirem-se os indicadores a partir de dados históricos e não somente do momento presente. Quanto aos indicadores sobre a formação na área portuária, podem-se buscar bases de dados estrangeiras e internacionais que contemplem informações, principalmente, dos grandes polos educacionais da área portuária, uma vez que é comum que lideranças brasileiras efetuem parte de sua formação acadêmica em instituições ligadas aos grandes portos internacionais, sobretudo europeus. Outra possibilidade de qualificação de um trabalho futuro que avance nos resultados aqui trazidos surge a partir da disponibilização de espaço para a manifestação feminina no que toca a temática. Entrevistas semiestruturadas com lideranças femininas do setor portuário ou mesmo estudiosas do mesmo setor seriam de grande valia e enriqueceriam os resultados.

\section{REFERÊNCIAS}

ABEPH - Associação Brasileira de Entidades Portuárias e Hidroviárias. Associados. Disponível em: https://www.abeph.com.br/associados. Acesso em: 25 mai. 2019.

ALESC - Assembleia Legislativa do Estado de Santa Catarina.

Deputados.Disponível em: http://www.alesc.sc.gov.br/todos-deputados. Acesso em: 20 mai. 2019.

CAPES - Coordenação de Aperfeiçoamento de Pessoal de Nível Superior. Coleta de dados: discentes da pós-gradução stricto-sensu do Brasil.2017. Disponível em: https://dadosabertos.capes.gov.br/dataset/coleta-de-dados-discentes-da-posgraduacao-stricto-sensu-do-brasil-2017/resource/7cc0dad6-3bab-4788-83f67a5a925a287b. Acesso em: 7 jun. 2019.

Catálogo de teses. Disponível em: https://catalogodeteses.capes.gov.br/catalogo-teses/\#!/. Acesso em: 7 jun. 2019.

CIDESPORT - Congresso Internacional de Desemp-enho Portuário.Edições anteriores. Disponível em: https://2019.cidesport.com.br/edicoes-anteriores/. Acesso em: 30 mai. $2019^{1}$.

Fale conosco. Disponível em: https://2019.cidesport.com.br/faleconosco/. Acesso em: 30 mai. $2019^{2}$.

CNPJ CONSULTAS. Consulte rapidamente o CNPJ da empresa através da busca pelo nome. Disponível em: https://www.cnpjconsultas.com/. Acesso em: 7 jun. 2019.

CNPQ - Conselho Nacional de Desenvolvimento Científico e Tecnológico. Painel Lattes. Disponível em: http://estatico.cnpq.br/painelLattes/sexofaixaetaria/. Acesso em: 5 jun. 2019. 


\section{CIDESPORT/2019}

Congresso Internacional

de Desempenho Portuário

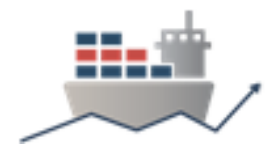

DUSSEL, Enrique. Filosofía de Liberación. 1977. Cidade do México: Edicol, 1977.

FORTUNE. Fortune 500. Disponível em:

http://fortune.com/fortune500/list/filtered?ceowoman=true. Acesso em: 10 jun. 2019.

IBGE - INSTITUTO BRASILEIRO DE GEOGRAFIA E ESTATÍSTICA. Pesquisa Nacional por Amostra de Domicílios Contínua: PNAD Contínua. Disponível em: https://www.ibge.gov.br/estatisticas-novoportal/sociais/trabalho/17270-pnadcontinua.html?\&t=o-que-e. Acesso em 08 fev. 2018.

INEP - Instituto Nacional de Estudos e Pesquisas Educacionais Anísio Teixeira. Estatísticas da educação superior. Disponível em:

http://inep.gov.br/web/guest/sinopses-estatisticas-da-educacao-superior. Acesso em: 1jun 2019.

IPU - InternationalParlamentary Union. Woman in politics: 2019. Disponível em: https://www.ipu.org/resources/publications/infographics/2019-03/women-in-politics2019. Acesso em: 5 jun. 2019.

LAVINAS, L.; VEIGA, A.; GUERREIRO, M. Estratégias femininas para conciliar trabalho remunerado e trabalho doméstico no século XXI. Revista da ABET, São Paulo, v. 10, n. 2, p. 56-79, jul./dez. 2011.

MIGNOLO, Walter. Local Histories/Global Designs: EssaysontheColonialityof Power, SubalternKnowledgesandBorderThinking. Princeton: Princeton University Press, 2000.

PNUD - PROGRAMA DAS NAÇÕES UNIDAS PARA O DESENVOLVIMENTO. Atlas do desenvolvimento humano no Brasil: Santa Catarina. Disponível em: http://atlasbrasil.org.br/2013/pt/perfil_uf/santa-catarina. Acesso em 08 fev. 2018.

PODER EXECUTIVO DO ESTADO DE SANTA CATARINA. Portal da transparência do Poder Executivo do Estado de Santa Catarina: remuneração dos servidores. Disponível em: http://www.transparencia.sc.gov.br/remuneracaoservidores. Acesso em: 9 jul. 2019.

PORTOSTRATEGY. The gender divide. 2017. Disponível em:

http://www.portstrategy.com/news101/administration/Personnel/gender-diversityfeature2. Acesso em 5 abr. 2019.

PORTO DE IMBITUBA. Porto de Imbituba. Disponível em:

http://www.portodeimbituba.com.br/site/index.php. Acesso em: 10 jul. 2019.

PORTO DE ITAJAÍ. Porto de Itajaí. Disponível em:

http://www.portoitajai.com.br/novo/. Acesso em: 10 jul. 2019.

PORTO DE ITAPOÁ. Porto de Itapoá. Disponível em:

http://www.portoitapoa.com.br/. Acesso em: 10 jul. 2019.

PORTO DE SÃO FRANCISCO DO SUL. Porto de São Francisco do Sul.

Disponível em: https://www.apsfs.sc.gov.br/. Acesso em: 10 jul. 2019. 


\section{CIDESPORT/2019}

Congresso Internacional

de Desempenho Portuário

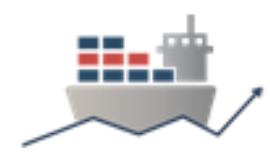

PORTODE SAN DIEGO. Executiveleadershipgroup. Disponível em:

https://www.portofsandiego.org/about-us/executive-leadership-group.html. Acesso em 08 fev. 2018.

PORTONAVE. Portonave. Disponível em:http://www.portonave.com.br/pt/. Acesso em: 10 jul. 2019.

PRESIDÊNCIA DA REPÚBLICA. Conheça a Presidência: ministros. Disponível em: http://www2.planalto.gov.br/conheca-a-presidencia/ministros. Acesso em: 1 jul. $2019^{2}$.

. Galeria de Presidentes. Disponível em:

http://www2.planalto.gov.br/conheca-a-presidencia/acervo/galeria-de-presidentes. Acesso em: 1 jul. 20191.

Governadores das unidades federativas do Brasil. Disponível em: http://www2.planalto.gov.br/acompanhe-planalto/imagens/2018/governadores-dasunidades-federativas-do-brasil/governadores-das-unidades-federativas-do-brasil26/view. Acesso em: 1 jul. $2019^{3}$.

UNIÃO EUROPEIA. Manual para a Integração da Dimensão da Igualdade de Gênero nas Políticas de Emprego. 2008. Conselho dos Ministros: Lisboa, 2008.

VIEIRA, Josênia Antunes. A identidade da mulher na modernidade. Delta, Brasília, v. 21, 2005, Universidade de Brasília. Disponível em: http://dx.doi.org/10.1590/S0102-44502005000300012. Acesso em: 10 jul. 2019.

WTF - AdvancingWoman in Transportation. About us. Disponível em: https://www.wtsinternational.org/about/. Acesso em: 10 jun. 2019. 